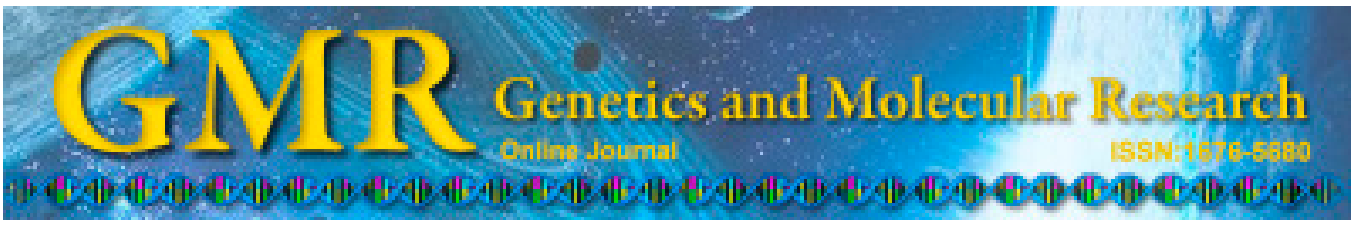

\title{
Blocking the expression of the hepatitis B virus $S$ gene in hepatocellular carcinoma cell lines with an anti-gene locked nucleic acid in vitro
}

\author{
Y.-B. Deng, H.-J. Qin, Y.-H. Luo, Z.-R. Liang and J.-J. Zou \\ Medical Examination Center of the Affiliated Hospital of Youjiang \\ Nationalities Medical College, Guangxi Province Baise City, China \\ Corresponding author: Y.-B. Deng \\ E-mail: dengyb75@163.com
}

Genet. Mol. Res. 14 (2): 5445-5451 (2015)

Received September 29, 2014

Accepted March 23, 2015

Published May 22, 2015

DOI http://dx.doi.org/10.4238/2015.May.22.14

\begin{abstract}
The aim of this study was to investigate the effects of inhibition of the hepatitis B virus (HBV) $S$ gene by polypurine region locked nucleic acid on viral replication in cells. We designed and synthesized a locked nucleic acid, phosphorothioate oligonucleotides, unmodified oligonucleotides, and unrelated control sequence for the hepatitis B virus $S$ gene polypurine region. HepG2.2.15 cells were transfected by cationic liposome, and fluorescence quantitative polymerase chain reaction technology (PCR) and time-resolved fluoroimmunoassay technology was utilized to monitor the content of HBV DNA, HbsAg, and $\mathrm{HBeAg}$ at 2, 4, 6, 8 and 10 days post-transfection. The effects on cell metabolism were detected by four methyl thiazolyl tetrazolium assay. The locked nucleic acid had an obvious effect on HBV DNA replication and $\mathrm{HBsAg}$ and $\mathrm{HBeAg}$ expression in a dose and time dependent manner. The inhibition rates were 52.14, 57.48, and 29.63\% after 6 days, respectively. The locked nucleic acid had no significant effect on cell metabolism. The HBV $S$ gene polypurine region locked nucleic acid could effectively inhibit the replication of HBV in vitro, and could pro-
\end{abstract}


vide an effective target for the treatment of HBV and a theoretical and experimental basis for anti-gene therapy.

Key words: Liposome; Hepatitis B virus; Locked nucleic acid; Anti-gene therapy

\section{INTRODUCTION}

Anti-gene therapy utilizes a local three helix structure which combines specific oligonucleotides with a target double-stranded DNA poly-pyrimidine or poly-purine region, preventing the association of target DNA, polymerase, and transcription factors to inhibit target gene replication and expression. Locked nucleic acids (LNAs) are recently identified cyclic nucleotide derivatives (Crouzier et al., 2012; Hildebrandt-Eriksen et al., 2012; Mishra et al., 2012; Robertson and Vora, 2012). Compared with other oligonucleotides, LNAs have better thermal stability, higher molecular hybridization ability, stronger resistance to nuclease degradation, better fat solubility, and lower cell toxicity. The results of previous studies have shown that the single strand antisense LNA for the HBV $S$ gene mRNA (Deng et al., 2010) and HBV preS1 (Deng and Wen 2013) gene dsDNA can effectively inhibit intracellular HBV replication. In order to further observe the inhibitory effects of LNA on intracellular HBV replication, this study targeted the most conservative $S$ gene region of HBV for design of the anti-gene LNA fragment. Transfection of the HepG2.2.15 cell line with the LNA mediated by cationic liposome allowed us to observe its antiviral effect, with the goal of identifying new, specific, and effective anti HBV drugs.

\section{MATERIAL AND METHODS}

\section{Material}

HepG2.2.15 cells comprise an HBV DNA (ayr subtype) whole gene transfection into a hepatocellular carcinoma cell line (China Type Culture Collection), which can stable secrete HBV particles, hepatitis B virus surface antigen (HBsAg), and hepatitis B virus e antigen (HBeAg). This cell line was routinely cultured in G418 (380ITI1) DMEM culture medium with 10\% fetal bovine serum, and passaged every 5-6 days under the growth conditions of $37^{\circ} \mathrm{C}$ and $5 \% \mathrm{CO}_{2}$. This experiment was conducted at the Medical Inspection Center of the Clinical College of Youjiang Nationalities Medical College. The DMEM medium and G418 were obtained from Gibco (Gaithersburg, MD, USA). Fetal bovine serum was purchased from Hangzhou Four Clear Company (Hangzhou, China). Lipofectamine2000 was obtained from Invitrogen (Carlsbad, CA, USA). The HBV DNA Kit was obtained from Shenzhen PG Biotech (Shenzhen, China). HBsAg and HbeAg quantitative assay kits were products of Suzhou New Wave Biological Technology Co., Ltd. (Suzhou, China).

\section{Methods}

\section{Design and synthesis of the anti-gene LNA}

We obtained the full sequence of HBV (U95551.1; GI:2182117) from the NCBI/ 
Genome database with the OligoWalk function of the RNA structure 5.0 software (BioMed Central, USA). According to the principle of oligonucleotide action and design, we designed and screened minimum total free energy oligonucleotide fragments which were complementary to the purine rich region of the HBV $S$ gene, modified as follows: 1) LNA: 5'-ACA Delta TCCA Delta GCGA Delta TA Delta GC-3'; 2) phosphorothioate oligonucleotides: 5'-ACA\#TCCA\#GCGA\#TA\#GC-3'; 3) unmodified oligonucleotides: 5'-ACATCCAGCGATA GC-3'; 4) irrespective of the sequence: 5'-GCGTGGCTAAGCGAT-3'. In each sequence, delta represents the LNA modification, and \# represents the $\mathrm{S}$ (sulfur) modification. Each sequence was excluded by BLAST and homologous with human, and was modified and purified by Gene Link (Hawthorne, NY, USA).

\section{Experimental design and liposome transfection}

This experiment was divided into experimental and control groups. The control group included a blank control group and an unrelated sequence group (unrelated SEQ). The experimental group included: 1) the unmodified oligonucleotide group (ODN), phosphorothioate oligonucleotide group (S-ODN), and anti-gene locked nucleic acid group (AG-LNA); 2) LNA groups consisted of 0.2, 0.4, 0.6, 0.8 and $1.0 \mu \mathrm{g} / \mathrm{L}$. HepG2.2.15 cells were inoculated into 16 well plates at $1 \times 10^{5}$ cells $/ \mathrm{mL}$ with $100 \mu \mathrm{L}$ on each well; 10 groups were established with and each group consisting of 6 wells. After the cells had adhered, $1 \mathrm{~mL}$ LNA liposome-DMEM mixture was added to each well. The supernatant liquid $(500 \mu \mathrm{L})$ was collected at 2, 4, 6, 8, and 10 days, respectively, and stored in $-20^{\circ} \mathrm{C}$ until transfection tests were performed according to the liposome operation manual.

\section{Determination of the content of $H B V D N A$ in supernatant culture}

The content of HBV DNA in supernatant culture was detected by real-time fluorescent quantitative polymerase chain reaction (PCR) assay. The cultured medium aliquot (50 $\mu \mathrm{L}$ ) was added to an equal volume DNA extract, mixed with constant temperature of $100^{\circ} \mathrm{C}$ and treated for $10 \mathrm{~min}$, followed by centrifugation for $5 \mathrm{~min}$ at $1200 \mathrm{r} / \mathrm{min}$. A $2 \mu \mathrm{L}$ sample of the supernatant culture was placed into a PCR reaction tube and added to the PCR reaction solution, to a the total volume of $25 \mu \mathrm{L}$. Amplification conditions were $37^{\circ} \mathrm{C}$ for $2 \mathrm{~min}$, $94^{\circ} \mathrm{C}$ pre-degeneration for $3 \mathrm{~min}, 94^{\circ} \mathrm{C}$ for $5 \mathrm{~s}$, and $60^{\circ} \mathrm{C}$ for $40 \mathrm{~s}$ for a total of 35 cycles. The automated computer software was utilized to analyze the collected fluorescence signal and to calculate the quantitative results. The HBV DNA copy number was calculated by the method of logarithmic mean value.

\section{Determination of the content of HbsAg and HBeAg in supernatant culture}

Each sample was repeated three times using a time-resolved immunofluorescence assay, in strict accordance with the kit and instrument manual. The concentration was represented by $\mathrm{g} / \mathrm{L}$.

\section{Detection of the cellular toxicity of the $L N A$}

To detect the effects of LNA on cell metabolic activity, the four methyl thiazolyl tetrazolium (MTT) colorimetric method was used. 


\section{Statistical analysis}

All data are reported as mean \pm standard deviation (means $\pm \mathrm{SD}$ ) and analyzed with the SPSS13.0 statistical software (SPSS, Chicago, IL, USA). Groups were compared with the repeated measurement analysis of designed variance LSD test. The inhibition rate was calculated as $(\%)=($ blank control group $\mathrm{N}$ - experimental group $\mathrm{N}) /$ control group $\mathrm{N} \times 100 \%(\mathrm{~N}$ : mean well numerical experiments).

\section{RESULTS}

\section{Effects of anti-gene LNA on intracellular viral gene replication and protein expres- sion}

A strong inhibitory effect of the anti-gene LNA was observed six days following addition of the oligonucleotide on the replication of viral DNA and the expression of HBsAg and HBeAg. The inhibition rates were 52.14, 57.48, and 29.63\%, respectively (Table 1).

\begin{tabular}{|c|c|c|c|}
\hline Groups & HBV DNA (copies/L) & $\mathrm{HBsAg}(\mu \mathrm{g} / \mathrm{L})$ & $\operatorname{HBeAg}(\mu \mathrm{g} / \mathrm{L})$ \\
\hline Blank control & $1.41 \pm 0.04$ & $1.67 \pm 0.02$ & $1.35 \pm 0.01$ \\
\hline Unrelated SEQ & $1.40 \pm 0.05$ & $1.65 \pm 0.02$ & $1.36 \pm 0.01$ \\
\hline ODN & $1.35 \pm 0.05$ & $1.53 \pm 0.02$ & $1.28 \pm 0.02$ \\
\hline S-ODN & $1.05 \pm 0.09$ & $1.06 \pm 0.06$ & $1.09 \pm 0.03$ \\
\hline AG-LNA & $0.67 \pm 0.03 *$ & $0.71 \pm 0.03 *$ & $0.95 \pm 0.02 *$ \\
\hline
\end{tabular}

$* \mathrm{P}<0.05$ compared with a blank control and an unrelated SEQ group. LNA = locked nucleic acid; HBV = hepatitis $\mathrm{B}$ virus; $\mathrm{SEQ}=$ sequence group; $\mathrm{ODN}=$ oligonucleotide group; S-ODN = phosphorothioate ODN; AG-LNA = anti-gene LNA.

\section{Effects of different doses of anti-gene LNA on the replication of intracellular viral genes and protein expression}

Increased inhibition of intracellular viral gene replication was observed six days following LNA addition, along with inhibition of the expression of HbsAg and HBeAg. Inhibition increased along with the increased concentration of drug, and the strongest inhibition concentration was $0.6 \mathrm{~g} / \mathrm{L}$. The inhibition rates were $60.99,57.96$, and $25.18 \%$, respectively (Table 2 ).

Table 2. Inhibitory effects of different doses of the anti-gene LNA on the replication and expression of the HBV $S$ gene in HepG2.2.15 cells.

\begin{tabular}{lccc}
\hline Groups & HBV DNA (copies/L) & HBsAg $(\mu \mathrm{g} / \mathrm{L})$ & HBeAg $(\mu \mathrm{g} / \mathrm{L})$ \\
\hline Blank control $(0.0 \mu \mathrm{g} / \mathrm{L})$ & $1.41 \pm 0.04$ & $1.57 \pm 0.02$ & $1.35 \pm 0.01$ \\
$0.2 \mu \mathrm{g} / \mathrm{L}$ & $0.91 \pm 0.05$ & $1.12 \pm 0.09$ & $1.15 \pm 0.03$ \\
$0.4 \mu \mathrm{g} / \mathrm{L}$ & $0.58 \pm 0.06$ & $0.74 \pm 0.03$ & $1.10 \pm 0.04$ \\
$0.6 \mu \mathrm{g} / \mathrm{L}$ & $0.55 \pm 0.05^{*}$ & $0.66 \pm 0.03^{*}$ & $1.01 \pm 0.05^{*}$ \\
$0.8 \mu \mathrm{g} / \mathrm{L}$ & $0.64 \pm 0.03$ & $0.73 \pm 0.04$ & $1.09 \pm 0.03$ \\
$1.0 \mu \mathrm{g} / \mathrm{L}$ & $0.68 \pm 0.06$ & $0.75 \pm 0.04$ & $1.12 \pm 0.04$ \\
\hline
\end{tabular}

$* \mathrm{P}<0.05$ compared with blank control group. $\mathrm{LNA}=$ locked nucleic acid; $\mathrm{HBV}=$ hepatitis $\mathrm{B}$ virus. 


\section{Effects of different duration of anti-gene LNA exposure on the replication of intra- cellular viral genes and protein expression}

The inhibition rates of anti-gene LNA on intracellular viral gene replication 2, 4, 6, 8 , and 10 days following LNA addition were $26.19,50,51.77,50.88$, and $48.80 \%$, respectively; the inhibition rates of HBsAg expression were $31.07,50.39,57.49,60.64$, and $60.09 \%$, respectively; and the inhibitory rates of HBeAg were 16.67, 27.43, 28.89, 31.07, and 24.02\%, respectively (Tables 3-5).

Table 3. Inhibitory effects of anti-gene LNA on the replication of HBV DNA in HepG2.2.15 cells at different times (means $\pm \mathrm{SD}$, copies $/ \mathrm{L}, \mathrm{N}=6$ ).

\begin{tabular}{lccccc}
\hline Groups & 2 days & 4 days & 6 days & 8 days & 10 days \\
\hline Blank control & $0.84 \pm 0.03$ & $1.18 \pm 0.04$ & $1.41 \pm 0.04$ & $1.71 \pm 0.03$ & $2.09 \pm 0.05$ \\
Unrelated SEQ & $0.87 \pm 0.06$ & $1.14 \pm 0.03$ & $1.40 \pm 0.05$ & $1.72 \pm 0.02$ & $1.98 \pm 0.06$ \\
ODN & $0.81 \pm 0.02$ & $1.11 \pm 0.04$ & $1.35 \pm 0.05$ & $1.66 \pm 0.02$ & $2.05 \pm 0.03$ \\
S-ODN & $0.71 \pm 0.02$ & $0.78 \pm 0.03$ & $1.05 \pm 0.09$ & $1.32 \pm 0.05$ & $1.70 \pm 0.05$ \\
AG-LNA & $0.62 \pm 0.02$ & $0.59 \pm 0.02^{*}$ & $0.68 \pm 0.03^{*}$ & $0.84 \pm 0.04^{*}$ & $1.07 \pm 0.08^{*}$ \\
\hline
\end{tabular}

$* \mathrm{P}<0.05$ compared with a blank control and an unrelated SEQ group. LNA = locked nucleic acid; HBV = hepatitis $\mathrm{B}$ virus; $\mathrm{SEQ}=$ sequence group; $\mathrm{ODN}=$ oligonucleotide group; $\mathrm{S}-\mathrm{ODN}=$ phosphorothioate $\mathrm{ODN} ; \mathrm{AG}-\mathrm{LNA}=$ anti-gene LNA.

Table 4. Inhibitory effects of anti-gene LNA on the expression of HBsAg in HepG2.2.15 cells at different times (means $\pm \mathrm{SD}$, copies $/ \mathrm{L}, \mathrm{N}=6$ ).

\begin{tabular}{lccccc}
\hline Groups & 2 days & 4 days & 6 days & 8 days & 10 days \\
\hline Blank control & $1.03 \pm 0.01$ & $1.29 \pm 0.02$ & $1.67 \pm 0.02$ & $1.88 \pm 0.02$ & $2.23 \pm 0.01$ \\
Unrelated SEQ & $0.99 \pm 0.01$ & $1.26 \pm 0.03$ & $1.71 \pm 0.02$ & $1.85 \pm 0.02$ & $2.21 \pm 0.02$ \\
ODN & $0.97 \pm 0.01$ & $1.22 \pm 0.03$ & $1.54 \pm 0.02$ & $1.71 \pm 0.02$ & $2.12 \pm 0.01$ \\
S-ODN & $0.85 \pm 0.02$ & $0.84 \pm 0.01$ & $1.06 \pm 0.06$ & $1.35 \pm 0.03$ & $1.75 \pm 0.04$ \\
AG-LNA & $0.71 \pm 0.01$ & $0.64 \pm 0.02^{*}$ & $0.71 \pm 0.03^{*}$ & $0.74 \pm 0.03^{*}$ & $0.89 \pm 0.04^{*}$ \\
\hline
\end{tabular}

$* \mathrm{P}<0.05$ compared with a blank control and an unrelated SEQ group. LNA = locked nucleic acid; HBV = hepatitis $\mathrm{B}$ virus; $\mathrm{SEQ}=$ sequence group; $\mathrm{ODN}=$ oligonucleotide group; S-ODN = phosphorothioate ODN; AG-LNA = anti-gene LNA.

Table 5. Inhibitory effects of anti-gene LNA on the expression of HBeAg in HepG2.2.15 cells at different times (means $\pm \mathrm{SD}$, copies/L, $\mathrm{N}=6$ ).

\begin{tabular}{lccccc}
\hline Groups & 2 days & 4 days & 6 days & 8 days & 10 days \\
\hline Blank control & $0.78 \pm 0.02$ & $1.13 \pm 0.02$ & $1.35 \pm 0.01$ & $1.77 \pm 0.01$ & $2.04 \pm 0.01$ \\
Unrelated SEQ & $0.75 \pm 0.02$ & $1.09 \pm 0.02$ & $1.36 \pm 0.02$ & $1.74 \pm 0.01$ & $1.99 \pm 0.01$ \\
ODN & $0.74 \pm 0.01$ & $1.05 \pm 0.02$ & $1.28 \pm 0.02$ & $1.71 \pm 0.04$ & $1.93 \pm 0.03$ \\
S-ODN & $0.71 \pm 0.02$ & $0.89 \pm 0.05$ & $1.09 \pm 0.03$ & $1.53 \pm 0.04$ & $1.87 \pm 0.03$ \\
AG-LNA & $0.65 \pm 0.02$ & $0.82 \pm 0.01^{*}$ & $0.96 \pm 0.02^{*}$ & $1.22 \pm 0.06^{*}$ & $1.55 \pm 0.05^{*}$ \\
\hline
\end{tabular}

$* \mathrm{P}<0.05$ compared with a blank control and an unrelated SEQ group. LNA $=$ locked nucleic acid; HBV $=$ hepatitis $\mathrm{B}$ virus; $\mathrm{SEQ}=$ sequence group; ODN = oligonucleotide group; $\mathrm{S}-\mathrm{ODN}=$ phosphorothioate $\mathrm{ODN}$; AG-LNA = anti-gene LNA.

\section{Effects of LNA on cell metabolism}

After 7 days treatment, the cell activity ( $A$ value) of the LNA group was $1.284+0.043$, which was not different from that of the control group $(1.255+0.038)$. 


\section{DISCUSSION}

Because HBV DNA polymerase lacks a proofreading function, it is relatively simple to produce a mutant virus in the process of replication, which results in a decreased susceptibility or resistance to drug treatments. Therefore, there is a need to identify drugs or therapies that can block the target gene combined with the viral polymerase and transcription factors. The $S$ gene region is one of the most important open reading frames of the HBV genome, encoding a protein molecule that is an important part of $\mathrm{HbsAg}$. Thus, the $S$ gene is not only closely related to virus replication, transcription, assembly, and secretion processes, but it is also related to the cellular and humoral immune response that is induced by virus infection.

We designed and synthesized an anti-gene LNA fragment based on the purine-rich region of the HBV $S$ gene, which we transfected into the HepG2.2.15 cell line via cationic liposome. We evaluated the efficacy of the LNA by detecting changes of HBV DNA, HBsAg, $\mathrm{HBeAg}$, and other indicators in the culture supernatant. The experimental results showed that the inhibitory effects of anti-gene LNA on the replication of HBV DNA and expression of HBsAg, HBeAg were more obvious than those produced by phosphorothioate oligonucleotides, which indicated that the design for the $S$ gene LNA had a strong inhibitory ability and was specifically targeted. The anti-gene LNA was also shown to have different inhibitory effects on intracellular viral gene replication and protein expression at different drug concentrations. The inhibitory rate increased with LNA concentration until a platform period emerged. The strongest inhibitory effects were observed when the LNA concentration was $0.6 \mathrm{~g} / \mathrm{L}$, potentially because a saturated state of nucleic acid molecules binding to liposome was reached. Further increase of the amount of nucleic acid adjacent to oligo liposome poly vesicle would be supposed to lead to fusion and formation of multilamellar vesicles, which would decrease the total surface area of lipid vesicles and result in a decrease of drug loading rate. The inhibition effects of anti-gene LNA were also time dependent: the inhibition rate increased with the prolongation of drug action time and reached a plateau period, followed by a gradual decrease. In addition, the results of MTT analysis demonstrated that the LNA had no obvious cell toxicity based on metabolic activity.

In summary, in vitro application of an anti-gene LNA molecule designed against the purine rich region of the HBV $S$ gene can effectively inhibit virus replication and viral gene expression, which might provide a theoretical and experimental basis for HBV anti-gene therapy.

\section{ACKNOWLEDGMENTS}

Research supported by a National Natural Science Fund Project (\#81460123).

\section{REFERENCES}

Crouzier L, Dubois C, Edwards SL, Lauridsen LH, et al. (2012). Efficient reverse transcription using locked nucleic acid nucleotide towards the evolution of nuclease resistant RNA aptamers. PLoS One 7: 35990.

Deng YB and Wen WR (2013). Anti-gene locked nucleic acid in vitro inhibits the hepatitis B virus pre S1 gene expression. Basic Clin. Med. 33: 722-725.

Deng YB, Zhang L and Wang YF (2010). HBV S gene antisense locked nucleic acid inhibits the replication of virus in vitro. Basic Clin. Med. 30: 360-363.

Hildebrandt-Eriksen ES, Aarup V, Persson R, Hansen HF, et al. (2012). A locked nucleic acid oligonucleotide targeting microRNA 122 is well-tolerated in cynomolgus monkeys. Nucleic Acid Ther, 22: 152-161.

Mishra S, Ghosh S and Mukhopadhyay R (2012). Ordered self-assembled locked nucleic acid(LNA) structures on gold 
(111) surface with enhanced single base mismatch recognition capability. Lanqmuir 28: 4325-4333.

Robertson KL and Vora GJ (2012). Locked nucleic acid flow cytometry-fluorescence in situ hybridization (LNA flowFISH): a method for bacterial small RNA detection. J. Vis. Exp. Jan 10: e3655. 